\title{
Improved Low-Voltage-Ride-Through
}

\section{Capability of Fixed-Speed Wind Turbines}

\section{using Decentralized Control of STATCOM}

\section{with Energy Storage System}

\author{
M. J. Hossain ${ }^{1}$, Member, IEEE, H. R. Pota ${ }^{2}$, and R. A. Ramos ${ }^{2}$, Senior Member, IEEE \\ ${ }^{2}$ Griffith School of Engineering, Griffith University, Gold Coast, QLD-4222, Australia. \\ E-mail: j.hossain@griffith.edu.au. \\ 22SEIT, UNSW@ADFA, Northcott Drive, Canberra, ACT-2600, Australia. \\ E-mail: h-pota@adfa.edu.au. \\ ${ }^{2}$ Engineering School of Sao Carlos, Av. Trabalhador Saocarlense, Brazil. \\ Email: ramos@sc.usp.br.
}

\begin{abstract}
The design and implementation of a new control scheme for reactive power compensation, voltage regulation and transient stability enhancement for wind turbines equipped with fixed-speed induction generators in large interconnected power systems is presented in this paper. The low-voltage-ride-through (LVRT) capability is provided by extending the range of the operation of the controlled system to include typical post-fault conditions. A systematic procedure is proposed to design decentralized multi-variable controllers for large interconnected power systems using minimax output-feedback control design method and the controller design procedure is formulated as an optimization problem involving rank-constrained linear matrix inequalities (LMIs). In this paper it is shown that STATCOM with energy storage system (STATCOM/ESS), controlled via robust control technique, is an effective device for improving the LVRT capability of fixed-speed wind turbines.
\end{abstract}

\section{INTRODUCTION}

Voltage instability is a growing concern for power systems worldwide due to the increasing impact of induction motor loads, wind turbines and other fast recovering load devices [1]. In this paper, the analysis and control of the response to relatively large perturbations in power systems with wind turbines coupled to squirrel cage induction generators (SCIG) is considered. Although the use of variable-speed wind turbines with power electronic interfaces is the current trend, many directly connected induction-generator-based wind turbines are still in operation. All wind turbine technologies, irrespective of type, employed in high-power wind farms, are required by new grid codes in some countries to have a fault ride-through capability for faults on the transmission system [2]. To deal with this situation, FACTS devices, such as a STATCOM, can be used. However, since STATCOMs are only able to provide reactive power control, their application is limited to 
reactive power support. To overcome this problem, STATCOM/ESS, e.g., can be used to supply the reactive power, increase the capability to damp electromechanical oscillations and enhance the LVRT capability of fixedspeed wind turbines. Although a STATCOM/ESS has great potential to fulfill the requirements of grid code to connect wind turbines, considerable advances in the control of this system are still needed for its practical implementation.

Recently a control method for limiting the torque and enhance the LVRT capability of grid-connected cage induction machines during the recovery process after grid faults by using a STATCOM is proposed in [3]. The authors in [4] propose a novel damping control algorithm for a STATCOM in a series compensated wind park for mitigating sub-synchronous resonance (SSR) and damping power system oscillations. An efficient control strategy to improve the LVRT capability in doubly fed induction generators is proposed in [5]. A proportionalintegral (PI)-based voltage and frequency controller is proposed in [6]. The existing control techniques are mainly aimed to maximize the output power, increase the reactive current during low-voltage, and reduce the peak rotor fault current. However, they do not consider the nonlinearity and interactions among wind farms. However, it is essential to consider the nonlinearity and interconnection effects in order to design controllers for multi-machine power systems, and also quantify the deviation of the operating point from the equilibrium point for which the system maintains closed-loop stability.

In recent years, the design of robust decentralized controllers for interconnected large power systems has been widely investigated and intensively studied with large attention on guaranteeing the stability of the overall system model in the presence of interconnections terms [7]. Although centralized controllers for such systems can often be designed using standard control design techniques, centralized control algorithms, in general, require a higher level of connectivity and higher communication costs compared to decentralized schemes. Hence, much effort has been focused on the application of decentralized control in power systems (see [7] and [8]). Results concerning robust decentralized control of interconnected power systems-based on approaches which explicitly take into account the interactions terms-have been reported in [9], [10]. In [11], an interesting decentralized turbine/governor controller scheme for power systems has been presented. However, the local state feedback controllers designed using this approach need the complete state information (which may not be feasible to obtain). An output-feedback robust decentralized control using LMI techniques has been presented in [12].

During faults and in post-fault operation the system state can be significantly far from the desired equilibrium point. In most situations the post-fault uncontrolled system has unstable post-fault trajectory. The difficulty in providing the LVRT capability is due to the nonlinearities in the power system model [13]. Linear controllers have a limited range of operation which normally does not include post-fault voltage conditions [13]. A solution to the LVRT problem is to design globally stabilizing controllers [14]. Unfortunately these controllers often need a full-state feedback and are not robust to modeling uncertainties. The next option is to use a linear controller which is robust to the change in the linear model with changing operating conditions-a necessary outcome of the underlying nonlinear model.

As mentioned above, robust controllers do exist for power systems but few of them have been able to systematically provide robustness against such large deviations as is required for LVRT. In this paper we present a method which can be used to design a linear controller which is robust to accommodate post-fault low-voltage conditions. We describe the design of robust decentralized controllers to enhance dynamic voltage and transient 
stability where instability is caused by large number of induction generators connected in the weak areas of the system. The controller is designed when the operating point is at a distance from the equilibrium point during transients. The extended robustness is provided by the exact linearization of the nonlinear model using the mean-value and the Cauchy remainder [15]. We also include interconnection effects from other machines in the controller design. Prior to the design of the controllers, a modal analysis has been carried out to identify the critical modes and the weakest machines, i.e., the ones that exert the greatest influence on the instability mechanism. By this approach, the potentially severe perturbations on the system are addressed in the controller design and this makes the proposed design procedure more robust with respect to nonlinear behaviors in the system.

The organization of the paper is as follows: Section 3 provides the mathematical modeling of the power system devices under consideration; test system and control objectives are presented in Section 4; Section 5 describes the linearization technique and the process for obtaining the bounds on the nonlinear terms; Section 6 discusses the decentralized minimax output-feedback controller design procedure using a rank-constrained LMI technique; Section 7 presents the control design algorithm and, in Section 8, the performance of the controller is outlined through a series of nonlinear simulation results. Concluding remarks and suggestions for future works are given in Section 9.

\section{LIST OF SYMBOLS}

Symbols in the order in which they appear.

$\begin{array}{llll}T_{a e}: \text { Aerodynamic torque } & \rho: \text { Air density } & A_{w t}: \text { Swept area } & \omega_{m}: \text { Rotor shaft speed } \\ c_{p}: \text { Power coefficient } & \lambda: \text { Tip-speed ratio } & \theta: \text { Pitch angle } & V_{w}: \text { Wind speed } \\ R: \text { Turbine rotor radius } & H_{m}, H_{G}: \text { Inertia constant } & K_{s}: \text { Torsion stiffness } & D_{m}, D_{G}: \text { Torsion damping } \\ \gamma: \text { Torsion angle } & f: \text { Normal grid frequency } & T_{e}: \text { Electrical torque } & N_{g}: \text { Gear ratio } \\ T_{m}: \text { Mechanical torque } & \omega_{G}: \text { Rotor speed of generator } & s: \text { Slip } & E_{q r}^{\prime}: \text { q-axis transient voltages } \\ R_{r}: \text { Rotor resistance } & T_{o}^{\prime}: \text { Transient time constant } & X_{s}: \text { Stator reactance } & X: \text { Rotor open-circuit reactance } \\ X_{r}: \text { Rotor reactance } & i_{d s}: \text { d-axis stator current } & X^{\prime}: \text { Transient reactance } & E_{d r}^{\prime}: \text { d-axis transient voltages } \\ V_{d s}: \text { d-axis stator voltage } & V_{q s}: \text { q-axis stator voltage } & v_{t}: \text { Terminal voltage } & i_{q s}: \text { q-axis stator current } \\ v_{d c}: \text { Capacitor voltage } & E_{d r}^{\prime}: \text { d-axis transient voltages } & C: \text { DC capacitor } & R_{C}: \text { Internal resistance of C } \\ \delta: \text { Rotor angle } & \alpha: \text { Firing angle of STATCOM } & m: \text { Modulation index } & P_{s}: \text { Input Power of STATCOMs } \\ K_{m}: \text { Sensor constant } & T_{m}: \text { Sensor time constant } & x: \text { State vector } & \mathrm{A}, \mathrm{B}, \mathrm{C}, \text { D: System matrices } \\ u: \text { Control input } & y: \text { Measured output } & \xi: \text { Uncertainty input } & \zeta: \text { Uncertainty output } \\ \Gamma: \text { Scaling parameter } & \phi, \psi: \text { Uncertainty gain matrix } & \tau, \theta: \text { Free parameter } & k: \text { inverter constant } \\ v_{s c}: \text { Supercapacitor voltage } & C_{s c}: \text { supercapacitance } & R_{s}: C_{s c} \text { resistance } & s_{c}: \text { Critical slip }\end{array}$

\section{Power System Model}

Dynamic models of the devices considered in the paper are presented in this section. In this research the following devices are used: (i) synchronous generators, (ii) fixed-speed wind generators and (iii) STATCOMs with energy storage devices. A single-axis third order generator model and an IEEE-ST1A type excitation system are used in this paper [16]. A fixed-speed wind generator is mainly equipped with a squirrel-cage 
induction generator. The nonlinear model of the wind turbines is based on a static model of the aerodynamics, a two mass model of the drive train and a third order model of the induction generator.

The rotor of the wind turbine, with radius $R_{i}$, converts energy from the wind to the rotor shaft, rotating at the speed, $\omega_{m_{i}}$. The power from the wind depends on the wind speed, $V_{w_{i}}$, the air density, $\rho_{i}$, and the swept area, $A_{w t_{i}}$. From the available power in the swept area, the power on the rotor is given based on the power coefficient, $c_{p_{i}}\left(\lambda_{i}, \theta_{i}\right)$, which depends on the pitch angle of the blade, $\theta_{i}$, and the ratio between the speed of the blade tip and the wind speed, denoted tip-speed ratio, $\lambda_{i}=\frac{\omega_{m_{i}} R_{i}}{V_{w_{i}}} . R_{i}$ is the wind turbine radius. The aerodynamic torque applied to the rotor for the $i^{\text {th }}$ turbine by the effective wind speed passing through the rotor is given as [17]:

$$
T_{a e_{i}}=\frac{\rho_{i}}{2 \omega_{m_{i}}} A_{w t_{i}} c_{p_{i}}\left(\lambda_{i}, \theta_{i}\right) V_{w_{i}}^{3}
$$

where $c_{p_{i}}$ is approximated by the following relation [18]:

$$
c_{p_{i}}=\left(0.44-0.0167 \theta_{i}\right) \sin \left[\frac{\pi\left(\lambda_{i}-3\right)}{15-0.3 \theta_{i}}\right]-0.00184\left(\lambda_{i}-3\right) \theta_{i},
$$

where $i=1, \cdots, n$, and $n$ is the number of wind turbines.

The drive train attached to the wind turbine converts the aerodynamic torque $T_{a e_{i}}$ on the rotor into the torque on the low speed shaft, which is scaled down through the gearbox to the torque on the high-speed shaft. A two-mass drive train model of a wind turbine generator system (WTGS) is used in this paper as the drive train modeling can satisfactorily reproduce the dynamic characteristics of the WTGS. The dynamics of the shaft are represented as [17]:

$$
\begin{aligned}
\dot{\omega}_{m_{i}} & =\frac{1}{2 H_{m_{i}}}\left[T_{a e_{i}}-K_{s_{i}} \gamma_{i}-D_{m_{i}} \omega_{m_{i}}\right], \\
\dot{\omega}_{G_{i}} & =\frac{1}{2 H_{G_{i}}}\left[K_{s_{i}} \gamma_{i}-T_{e_{i}}-D_{G_{i}} \omega_{G_{i}}\right], \\
\dot{\gamma}_{i} & =2 \pi f\left(\omega_{m_{i}}-\frac{1}{N_{g_{i}}} \omega_{G_{i}}\right) .
\end{aligned}
$$

The transient model of a induction generator (IG) is described in this paper by the following equations [19], [17]:

$$
\begin{aligned}
& \dot{s}_{i}=\frac{1}{2 H_{G_{i}}}\left[T_{m_{i}}-T_{e_{i}}\right], \\
& \dot{E}_{q r_{i}}^{\prime}=-\frac{1}{T_{o_{i}}^{\prime}}\left[E_{q r_{i}}^{\prime}-\left(X_{i}-X_{i}^{\prime}\right) i_{d s_{i}}\right]-s_{i} \omega_{s} E_{d r_{i}}^{\prime}, \\
& \dot{E}_{d r_{i}}^{\prime}=-\frac{1}{T_{o_{i}}^{\prime}}\left[E_{d r_{i}}^{\prime}+\left(X_{i}-X_{i}^{\prime}\right) i_{q s_{i}}\right]+s_{i} \omega_{s} E_{q r_{i}}^{\prime}, \\
& V_{d s_{i}}=R_{s_{i}} i_{d s_{i}}-X_{i}^{\prime} i_{q s_{i}}+E_{d r_{i}}^{\prime}, \\
& V_{q s_{i}}=R_{s_{i}} i_{d s_{i}}+X_{i}^{\prime} i_{q s_{i}}+E_{q r_{i}}^{\prime}, \\
& v_{t_{i}}=\sqrt{V_{d s_{i}}^{2}+V_{q s_{i}}^{2}},
\end{aligned}
$$

where $X_{i}^{\prime}=X_{s_{i}}+X_{m_{i}} X_{r_{i}} /\left(X_{m_{i}}+X_{r_{i}}\right), X_{i}=X_{s_{i}}+X_{m_{i}}, T_{o_{i}}^{\prime}=\left(L_{r_{i}}+L_{m_{i}}\right) / R_{r_{i}}$ and $T_{e_{i}}=E_{d r_{i}} i_{d s_{i}}+$ $E_{q r_{i}} i_{q s_{i}}$.

The STATCOM is a shunt-connected device using power electronics to generate a three-phase voltage whose magnitude and phase angle can be adjusted rapidly. In this way, the STATCOM can inject capacitive or inductive current at the AC system bus. The traditional STATCOM has limited energy storage capability. Thus it is not 
possible to significantly impact both active and reactive power simultaneously with the traditional STATCOM. The fast active and reactive power support provided by an ESS (which may consist as a supercapacitor coupled to the STATCOM, for example) can significantly enhance the flexibility and control of transmission and distribution systems.

The main components of the STATCOM/ESS shown in Fig. 1 are a normal STATCOM and a supercapacitor based energy storage system. A normal STATCOM is comprised of a coupling transformer, a voltage source inverter (VSC), and a DC link capacitor (usually an electrolytic). The DC link capacitor provides voltage support for the VSC and the DC chopper. The energy storage system is comprised of a supercapacitor and a bidirectional DC-DC buck-boost converter to control the charging and discharging of the supercapacitor modules. The aim of these modules is to store energy in the supercapacitor and then deliver that energy to the grid via the DC link when required. The DC to DC converter operates in buck mode to recharge the supercapacitor, whereas boost mode transfers the stored energy to the DC link [20].

We can write equations for the STATCOM circuit as:

$$
\dot{v}_{d c_{l}}(t)=-\frac{P_{s_{l}}}{C_{l} v_{d c_{l}}}-\frac{v_{d c_{l}}}{R_{c_{l}} C_{l}}
$$

for $l=1,2, \ldots, m$, where $m$ is the number of STATCOMs and $P_{s_{l}}$ is the power supplied by the system to the STATCOM to charge the capacitor, given by

$$
P_{s_{l}}=\left|E_{l}\right|^{2} G_{l l}+\sum_{\substack{p=1 \\ p \neq l}}^{m}\left|E_{l}\right|\left|E_{p}\right|\left[B_{l p} \sin \alpha_{p l}+G_{l p} \cos \alpha_{l p}\right]+\sum_{\substack{j=1 \\ j \neq l}}^{n}\left|E_{l}\right|\left|E_{j}^{\prime}\right|\left[B_{l j} \sin \left(\delta_{j}-\alpha_{l}\right)+G_{l j} \cos \left(\delta_{j}-\alpha_{l}\right)\right],
$$

where $G_{l p}$ and $B_{l p}$ are the real and imaginary parts of the equivalent transfer impedances between the terminal buses of STATCOMs, $l$ and $p$ and $G_{l j}$ and $B_{l j}$ are between terminal buses of STATCOM, $l$ and induction generator, $j$. The term $E_{j}^{\prime}$ denotes $E_{d r j}^{\prime}, E_{q r j}^{\prime}$ and $E_{q j}^{\prime}$, and $\sin \alpha_{p l}=\sin \left(\alpha_{p}-\alpha_{l}\right)$. Also, the STATCOM terminal AC voltage is $E_{l}=k_{l} v_{d c_{l}} \angle \alpha_{l}$, where $\alpha_{l}$ is the bus angle of the STATCOM in the reduced network, and $k_{l}=\sqrt{\frac{3}{8}} m_{l}$, where $m_{l}$ is the modulation index. The terminal voltages of the STATCOMs are measured using transducers with first order dynamic models of type:

$$
\dot{v}_{t m_{l}}=-\frac{v_{t m_{l}}}{T_{m_{l}}}+K_{m_{l}} v_{t_{l}} .
$$

The dynamics of the supercapacitor is represented as:

$$
C_{s c_{i}} \dot{v}_{d c_{r}}(t)=-\frac{v_{s c_{r}}}{R_{s_{r}}}-\frac{v_{d c_{l}}}{R_{s_{r}}}
$$

for $r=1,2, \ldots, p$, where $p$ is the number of ESS.

The STATCOM/ESS controller is depicted in Fig. 1. The controller provides DC voltage and terminal voltage command to achieve the desired system response during the transient period. The controller converts the voltage command into PWM switching signals for the STATCOM/ESS. The designed multi-variable controller regulates the modulation gain $m_{i}$ and firing angle $\left(\alpha_{i}\right)$. The firing angle $\alpha_{i}$ mainly affects the variation of the active power exchanged between the system whose input signal is the error signal between the measured DC voltage $V_{d c}$ and the specified power reference $\left(V_{d c_{r} e f}\right)$. Therefore, the function of the active power control is to meet the active power demand of the system during transients. The other output of the controller is the duty cycle 
TABLE I

CRITICAL Modes AND PARTicipation Factors

\begin{tabular}{|c|c|c|c|}
\hline Modes & \multicolumn{3}{|c|}{ Participation factors } \\
\hline$-0.062 \pm j 2.21$ & $\triangle \delta_{6}=1$ & $\triangle \delta_{1}=0.7738$ & $\triangle E_{d r 1}=0.74$ \\
\hline 0.018 & $\triangle E_{q r 2}^{\prime}=1$ & $\triangle E_{d r 2}^{\prime}=0.52$ & $\triangle s_{2}=0.49$ \\
\hline 0.14 & $\triangle E_{q r 4}^{\prime}=1$ & $\triangle E_{d r 4}^{\prime}=0.93$ & $\triangle s_{4}=0.29$ \\
\hline
\end{tabular}

ratio $m_{i}$ which mainly regulates the magnitude of the STATCOM's output voltage and therefore the system voltage.

\section{Test System AND CONTROL TASK}

One-line diagram of the New England system [21] is shown in Fig 2. This system is modified by replacing four conventional generators at buses 31-34 by four wind farms and used as the test system in this paper. The modified system network consists of six thermal power plants, and four wind farms. The conventional generation, wind generation, and the total load in this system are $3760.48 \mathrm{MW}, 2432.93 \mathrm{MW}$, and 6150.5 MW respectively. We use aggregated wind generator [22] and synchronous generator models [23] for controller design.

Two $150 \mathrm{kVA}$ 2-level VSC based STATCOM/ESS (95 F, $19 \mathrm{~kJ}$ ) are connected to the system at buses 32 and 34 through shunt coupling transformers at $110 \mathrm{kV}$ to regulate their respective terminal bus voltages at the point of common coupling (PCC). The most effective locations and best feedback signals for the STATCOM/ESS and power system stabilisers (PSSs) are found by the method of comparing the residues, which are the products of modal controllability and observability gramians [24]. The modal controllability indicates the degree of influence of the given input to the mode in question. The modal observability is a measure of the modal information contained in a feedback signal. They are independent and hence can be computed separately. Buses 36 and 39 are the best locations for the PSSs. The selection of the STATCOM/ESSs and PSSs locations and the best feedback signal are made by comparison of the residues at all locations.

The eigenvalue analysis of the original system (before replacing the conventional generation by wind farms) shows that it has a dominant mode at $-0.0131 \pm j 0.711$ with a damping ratio of 0.019 . The modified system has three critical modes and their values with the most significant normalized participation vectors are shown in Table I. The mode $-0.062 \pm j 2.21$ is an electromechanical mode with a damping ratio of 0.028 . The other two unstable modes with eigenvalues 0.018 and 0.14 are monotonic modes associated with both the rotor electrical dynamics of induction generators. These two monotonic modes are introduced due to the replacement of synchronous generation with induction generators. In this paper, attention is directed to the design of robust control for these unstable modes. From the participation vectors in Table I, it is clear that the generators 6 and 1 , and wind farms 1 and 2 contribute significantly to the dominant mode and the controllers should be designed for both the synchronous and wind generators. This emphasizes the need to design decentralized controllers.

The test system considered in this paper is divided into four subsystems based on the coherent groups (generators swing together) of generating units: (i) wind farms 1 and 3, (ii) wind farms 2 and 4, (iii) $G_{6}, G_{9}$, and $G_{10}$ and (iv) $G_{7}, G_{8}$, and $G_{1}$. One STATCOM/ESS controller each is a part of subsystems 1 and 2 , and 
PSSs are parts of subsystems 3 and 4. The PSSs are designed using the standard process given in [25]. For subsystems 1 and 2, the state vector is $\triangle x_{i}=\left[\triangle \omega_{m_{i}}, \triangle \omega_{G_{i}}, \triangle \gamma_{i}, \triangle s_{i}, \triangle E_{d r_{i}}^{\prime}, \triangle E_{q r_{i}}^{\prime}, \triangle v_{d c_{i}}, \triangle v_{t m_{i}}, \triangle v_{s c_{i}}\right]$, $\mathrm{i}=1$, 2. For STATCOM/ESS controllers, the control input $u_{i}=\left[\begin{array}{ll}\triangle m_{i} & \triangle \alpha_{i}\end{array}\right]^{T}, y_{i}=\left[\begin{array}{ll}\triangle v_{t_{i}} & \triangle v_{d c_{i}}\end{array}\right]^{T}$, and for (PSSs), $u_{i}=\triangle V_{s_{i}}$ and $y_{i}=\triangle \omega_{i}$, where $V_{s_{i}}$ is the PSS output signal and $\omega_{i}$ is the rotor speed of the synchronous generator.

\section{Problem Formulation}

A linearized model of the power system is usually obtained by expanding the equations, around an equilibrium point, in a Taylor series and retaining only the linear terms. In this paper, in the design of the linear controller, the Cauchy remainder is incorporated as an uncertain term thus quantifying the deviations from the equilibrium point.

The reformulation proposed in this paper using Cauchy remainder allows us to represent the nonlinear large scale power system $S$ comprising $n$ subsystems $S_{i}$ of the following form:

$$
\begin{aligned}
S_{i}: \triangle \dot{x}_{i} & =A_{i} \triangle x_{i}+B_{i} \triangle u_{i}+E_{i} \xi_{i}+L_{i} r_{i}, \\
z_{i} & =C_{i} \triangle x_{i}+D_{i} \triangle u_{i} \\
\zeta_{i} & =H_{i} \triangle x_{i}+G_{i} \triangle u_{i} \\
y_{i} & =C_{y i} \triangle x_{i}+D_{y i} \xi_{i}
\end{aligned}
$$

where $\triangle x_{i}$ is the state vector, $\triangle u_{i}$ is the control input, $y_{i}$ is the measured output, $z_{i}$ is the controlled output, $\xi_{i}$ is known as the uncertainty input, $\zeta_{i}$ is known as the uncertainty output, and $r_{i}$ describes the effect of other subsystems $S_{1}, \ldots, S_{i-1}, S_{i+1}, \ldots, S_{N}$ on subsystem $S_{i}$.

The procedure for obtaining the matrices in (15)-(18) and the bounding uncertainty is described in the rest of this section for the wind turbine and generator subsystem. The process is similar for the other subsystems. Let $\left(x_{i_{0}}, u_{i_{0}}\right)$ be an arbitrary point, using the mean-value theorem, the subsystem (2)-(10) with a wind turbine and a generator can be rewritten as follows [26]:

$$
\dot{x}_{i}=f_{i}\left(x_{i_{0}}, u_{i_{0}}\right)+P_{i}\left(x_{i}-x_{i 0}\right)+Q_{i}\left(u_{i}-u_{i_{0}}\right)+\sum_{\substack{j=1 \\ j \neq i}}^{n} N_{i}\left(x_{j}-x_{j_{0}}\right)
$$

where the Cauchy remainder terms are:

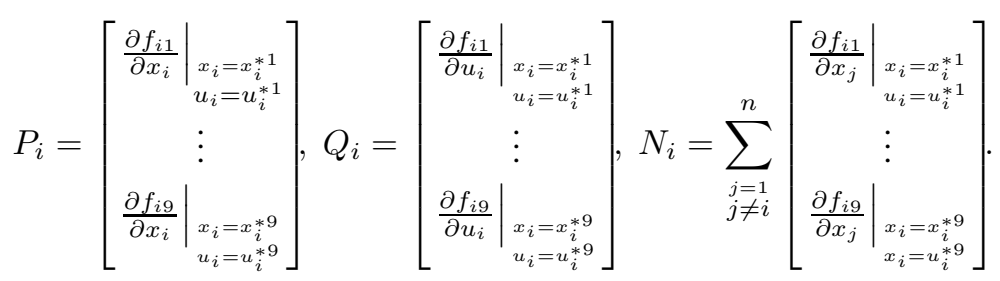

Here $x_{i}$ is a $1 \times 9$ column vector, $f_{i}=\left[f_{i 1}, \ldots, f_{i 9}\right]^{T}$ is also a $1 \times 9$ column vector made up of the right-handside of equations (2)-(10); $\left(x_{i}^{* p}, u_{i}^{* p}\right), p=1, \ldots, 9$, denote points lying on the line segment connecting points $\left(x_{i}, u_{i}\right)$ and $\left(x_{i_{0}}, u_{i_{0}}\right)$. Equation (19) is an exact reformulation of the system in which the first term is linear and the rest of the terms are Cauchy remainders. The Cauchy remainder term can also be linear but it has to be evaluated not at the system equilibrium point but on a point lying on the segment joining the equilibrium point and the current operating point. It should be noted that the exact values of $x_{i}^{* p}$ and $u_{i}^{* p}$ are not available, 
and due to this, instead of the exact expressions for $P_{i}, Q_{i}$ and $N_{i}$ in system (19), their bounds, obtained numerically, are used in the control design.

Letting $\left(x_{i 0}, u_{i 0}\right)$ be an equilibrium point and defining $\Delta x_{i} \triangleq x_{i}-x_{i 0}$ and $\Delta u_{i} \triangleq u_{i}-u_{i 0}$, it is possible to rewrite (19) as follows

$$
\begin{aligned}
\Delta \dot{x}_{i} & =\dot{x}_{i}-\dot{x_{i 0}}, \\
& =P_{i}\left(x_{i}-x_{i 0}\right)+Q_{i}\left(u_{i}-u_{i 0}\right)+N_{i}\left(x_{j}-x_{j 0}\right), \\
& =A_{i} \triangle x_{i}+\left(P_{i}-A_{i}\right) \triangle x_{i}+\left(Q_{i}-B_{i}\right) \triangle u_{i}+N_{i} \triangle x_{j}+B_{i} \triangle u_{i},
\end{aligned}
$$

where $A_{i}=\left.\frac{\partial f_{i}}{\partial x_{i}}\right|_{\substack{x_{i}=x_{i 0} \\ u_{i}=u_{i 0}}}$ and $B_{i}=\left.\frac{\partial f_{i}}{\partial u_{i}}\right|_{\substack{x_{i}=x_{i 0} \\ u_{i}=u_{i 0}}}$ are the Jacobian matrices evalutated about the point $\left\{x_{i 0}, u_{i 0}\right\}$. It is important to notice that both $A_{i}$ and $B_{i}$ are known matrices (jacobians evaluated at the equilibrium point) while $P_{i}$ and $Q_{i}$ are unknown, because they depend on the $x^{* p}$ and $u^{* p}$. Therefore, we use a formulation with bounded uncertainties to account for the terms in which these unknown matrices appear.

The system (20) is of the form which allows for an application of the minimax control design technique [27]. To apply this technique, we rewrite system (20) in terms of the block diagram shown in Fig. 3.

Let

$$
\left(P_{i}-A_{i}\right) \triangle x_{i}+\left(Q_{i}-B_{i}\right) \triangle u_{i}=E_{i} \xi_{i}
$$

where

$$
\begin{gathered}
E_{i}=\operatorname{diag}\left(\frac{1}{2 H_{m_{i}}}, \frac{1}{2 H_{G_{i}}}, 0, \frac{1}{2 H_{G_{i}}}, \frac{X_{i}-X_{i}^{\prime}}{T_{o_{i}}^{\prime}}, \frac{X_{i}-X_{i}^{\prime}}{T_{o_{i}}^{\prime}}, \frac{1}{C_{i}}, T_{m_{i}}, 0\right), \\
\xi_{i}=\tilde{\phi}_{i}\left(\tilde{H}_{i} \triangle x_{i}\right)+\tilde{\psi}_{i}\left(\tilde{G}_{i} \triangle u_{i}\right), N_{i} \triangle x_{j}=L_{i} r_{i},
\end{gathered}
$$

where $r_{i}=\sum_{\substack{j=1 \\ j \neq i}}^{n} \tilde{\Xi}_{i} \zeta_{j}$, and

$$
H_{i}=\sqrt{\Gamma_{i}}\left[\begin{array}{ccccccccc}
0 & 0 & 0 & 1 & 0 & 0 & 0 & 0 & 0 \\
0 & 0 & 0 & 0 & 1 & 0 & 0 & 0 & 0 \\
0 & 0 & 0 & 0 & 0 & 1 & 0 & 0 & 0 \\
0 & 0 & 0 & 0 & 0 & 0 & 1 & 0 & 0
\end{array}\right], G_{i}=\left[\begin{array}{ll}
1 & 1 \\
1 & 1 \\
1 & 1 \\
1 & 1
\end{array}\right],
$$

and $L_{i}$ is a $7 \times 7$ identity matrix.

Nonlinear functions $\tilde{\phi}_{i}$ and $\tilde{\psi}_{i}$ are obtained from the Jacobian matrices $P_{i}, A_{i}, Q_{i}$, and $B_{i}$. It is difficult to represent these matrices symbolically but it is straightforward to evaluate them numerically at a given point and this is what we need to do to calculate the bounds on $\tilde{\phi}_{i}$ and $\tilde{\psi}_{i}$ over the region of interest. To get an idea of the form of the expressions, we give here a few sample expressions. Let $\tilde{\phi}_{i}=\left[\tilde{\phi}_{i 1}, \cdots, \tilde{\phi}_{i 9}\right]^{T}$, where

$$
\tilde{\phi}_{i 1}=\left[\begin{array}{llll}
0 & 0 & 0 & 0 .
\end{array}\right], \tilde{\phi}_{i 2}=\left[\begin{array}{c}
x_{11} \\
x_{12} \\
x_{13} \\
x_{14} \\
x_{15} \\
x_{16}
\end{array}\right]^{T}\left[\begin{array}{llll}
0 & y_{12} & y_{13} & 0 \\
0 & y_{22} & y_{23} & 0 \\
0 & y_{32} & y_{33} & 0 \\
0 & y_{42} & y_{43} & 0 \\
0 & y_{52} & y_{53} & y_{54} \\
0 & y_{62} & y_{63} & y_{64}
\end{array}\right],
$$


where

$$
\begin{aligned}
& x_{11}=\cos \delta_{j i}^{*}-\cos \delta_{j i 0}, x_{12}=\sin \delta_{j i}^{*}-\sin \delta_{j i 0}, x_{13}=\cos \left(\delta_{m_{k}}^{*}-\delta_{i}^{*}\right)-\cos \left(\delta_{m_{k 0}}-\delta_{i 0}\right), \\
& x_{14}=\sin \left(\delta_{m_{k}}^{*}-\delta_{i}^{*}\right)+\sin \left(\delta_{m_{k 0}}-\delta_{i 0}\right), y_{12}=\sum_{j=1}^{n}\left(E_{d r_{j}}^{\prime *}-E_{d r_{j 0}}^{\prime}\right) G_{i j}+\sum_{j=1}^{n}\left(E_{q r_{j}}^{\prime *}-E_{q r_{j 0}}^{\prime}\right) B_{i j}, \\
& y_{22}=-\sum_{j=1}^{n}\left(E_{d r_{j}}^{\prime *}-E_{d r_{j 0}}^{\prime}\right) B_{i j}+\sum_{j=1}^{n}\left(E_{q r_{j}}^{\prime *}-E_{q r_{j 0}}^{\prime}\right) G_{i j}, y_{32}=\sum_{k=1}^{n}\left(E_{q_{k}}^{\prime *}-E_{q_{k 0}}^{\prime}\right) B_{i k}, \\
& x_{15}=\cos \left(\alpha_{l}^{*}-\delta_{i}^{*}\right)-\cos \left(\alpha_{l 0}-\delta_{i 0}\right), y_{42}=\sum_{k=1}^{n}\left(E_{q_{k}}^{\prime *}-E_{q_{k 0}}^{\prime}\right) G_{i k}, x_{16}=\sin \left(\alpha_{l}^{*}-\delta_{i}^{*}\right)-\sin \left(\delta_{l 0}-\delta_{i 0}\right), \\
& y_{52}=-\sum_{l=1}^{n} k_{l}\left(v_{d c_{l}}^{*^{\prime}}-v_{d c_{l 0}}\right) B_{i l}, y_{62}=\sum_{l=1}^{n} k_{l}\left(v_{d c_{l}}^{*^{\prime}}-v_{d c_{l 0}}\right) G_{i l}, y_{13}=\sum_{j=1}^{n}\left(E_{d r_{j}}^{\prime *}-E_{d r_{j 0}}^{\prime}\right) B_{i j}+\sum_{j=1}^{n}\left(E_{q r_{j}}^{\prime *}-E_{q r_{j 0}}^{\prime}\right) G_{i j}, \\
& y_{23}=-\sum_{j=1}^{n}\left(E_{d r_{j}}^{*}-E_{d r_{j 0}}^{\prime}\right) G_{i j}-\sum_{j=1}^{n}\left(E_{q r_{j}}^{\prime *}-E_{q r_{j 0}}^{\prime}\right) B_{i j}, y_{33}=\sum_{k=1}^{n}\left(E_{q_{k}}^{\prime *}-E_{q_{k 0}}^{\prime}\right) G_{i k}, y_{43}=-\sum_{k=1}^{n}\left(E_{q k}^{*}-E_{q_{k 0}}^{\prime}\right) B_{i k}, \\
& y_{53}=\sum_{l=1}^{n} \kappa_{l}\left(v_{d c_{l}}^{\prime^{\prime}}-v_{d c_{l 0}}\right) G_{i l}, y_{63}=\sum_{l=1}^{n} \kappa_{l}\left(v_{d c_{l}}^{*^{\prime}}-v_{d c_{l 0}}\right) B_{i l}, y_{54}=\sum_{l=1}^{n} \kappa_{l}\left(E_{d r_{i}}^{\prime *}-E_{d r_{i 0}}^{\prime}\right) B_{i l}+\sum_{l=1}^{n}\left(E_{q r_{i}}^{\prime *}-E_{q r_{i 0}}^{\prime *}\right) G_{i l}, \\
& y_{64}=\sum_{l=1}^{n} \kappa_{l}\left(E_{d r_{i}}^{\prime *}-E_{d r_{i 0}}^{\prime}\right) G_{i l}+\sum_{l=1}^{n}\left(E_{q r_{i}}^{\prime *}-E_{q r_{i 0}}^{\prime *}\right) G_{i l} .
\end{aligned}
$$

Given that uncertainties in this paper derive from nonlinearities, the term that have linear relations with the state variables will be represented by zeros in the corresponding matrices. The rest of the expressions of $\tilde{\phi}_{i}, \tilde{\psi}_{i}$, and $\tilde{\Xi}_{i}$ can be determined in a similar way as in [15].

The system (20) now can be rewritten as

$$
\triangle \dot{x}_{i}=A_{i} \triangle x_{i}+B_{i} \triangle u_{i}+E_{i} \xi_{i}+L_{i} r_{i}
$$

Next we introduce a scaling parameter $\Gamma_{i}$ such that the product terms $\tilde{\phi}_{i} \tilde{H}_{i}$ and $\tilde{\psi}_{i} \tilde{G}_{i}$, are factored into two parts. We define

$$
H_{i}=\sqrt{\Gamma_{i}} \tilde{H}_{i}, \quad \text { and } G_{i}=\sqrt{\Gamma_{i}} \tilde{G}_{i},
$$

from this it can be seen that $\Gamma_{i}$ is a scaling factor which affects the magnitude of the uncertain output $\zeta_{i}$. Scaling permits us to obtain less conservative results. We write

$$
\phi_{i}=\frac{1}{\sqrt{\Gamma_{i}}}\left[\begin{array}{ll}
\tilde{\phi}_{i} & \tilde{\psi}_{i}
\end{array}\right] \text { and } \Xi_{i}=\frac{1}{\sqrt{\Gamma_{i}}} \tilde{\Xi}_{i} .
$$

Finally the value of $\Gamma_{i}$ is chosen such that

$$
\left\|\phi_{i}\right\|^{2} \leq 1, \quad \text { and } \quad\left\|\Xi_{i}\right\|^{2} \leq 1
$$

From (22) and (28) we have

$$
\left\|\xi_{i}\right\|^{2} \leq \Gamma_{i}\left\|\tilde{H}_{i} \triangle x_{i}+\tilde{G}_{i} \triangle u_{i}\right\|^{2}
$$

We also define $\zeta_{i}=\tilde{H}_{i} \triangle x_{i}+\tilde{G}_{i} \triangle u_{i}$, and from this, we recover the norm bound constraints [28],

$$
\left\|\xi_{i}\right\|^{2} \leq\left\|\zeta_{i}\right\|^{2}, \quad \text { and } \quad\left\|r_{i}\right\|^{2} \leq \sum_{j \neq i}\left\|\zeta_{j}\right\|^{2}
$$

The bounds given in (30) can be used with the minimax output-feedback control design method to obtain a controller for the underlying nonlinear system. Robustness properties of the minimax output controller ensure that this controller stabilizes the nonlinear system (15)-(18) for all instances of linearization errors. The relationship between the maximum size of $\phi_{i}$ and the elements in (24) is complicated and not easy to see. Two observations are useful: (a) larger values of elements in $G$ and $B$ matrix lead to larger size of $\phi_{i}$, and (b) the maximum value of $\phi_{i}$ is not achieved at the corner points of the polytope but at interior points.

Equations (15)-(18) provide a new representation of the power system model with a linear part, and another part with higher order terms. For this controller design, we consider

$$
\begin{aligned}
& C_{i}=[0,0,0,1,0,0,0,0,0]^{T}, D_{i}=10^{-4}[1,1]^{T}, \\
& C_{y i}=[0,0,0,0,0,0,0,1,0 ; 0,0,0,0,0,0,0,0,1]^{T}, \\
& D_{y i}=10^{-4}[0,0,0,1,1,1,1,0,0 ; 0,0,0,1,1,1,1,0,0]^{T} .
\end{aligned}
$$

The new formulation presented in this section is used with the minimax output-feedback control theory to design decentralized controllers for the nonlinear power system. 


\section{Decentralized Control Design Using Rank Constrained LMis}

In this paper, a decentralized minimax output-feedback control has been designed using LMI techniques [28], [29]. The control design procedure given in [28] has been modified here for a single mode.

The robust control design methodology developed in [28] makes use of integral quadratic constraints (IQC) to characterize the magnitude of uncertain perturbations and interconnection between subsystems,

$$
\begin{aligned}
& E \int_{0}^{t_{l}}\left(\left\|\zeta_{i}(t)\right\|^{2}-\left\|\xi_{i}(t)\right\|^{2}\right) d t>-x_{i 0}^{T} M_{i} x_{i 0} \\
& E \int_{0}^{t_{l}}\left(\sum_{n=1, n \neq i}^{N}\left\|\zeta_{n}(t)\right\|^{2}-\left\|r_{i}(t)\right\|^{2}\right) d t>-x_{i 0}^{T} \bar{M}_{i} x_{i 0}
\end{aligned}
$$

where $M_{i}=M_{i}^{T}>0, \bar{M}_{i}=\bar{M}_{i}^{T}>0,\left\{t_{l}\right\}_{l=1}^{\infty}, t_{l} \rightarrow+\infty$, is a sequence of time instants and $E$ is the expectation operator. It is immediate that the constraints (30) can be rewritten in the form of (34) and (35) with arbitrarily chosen small $x_{i 0}^{T} M_{i} x_{i 0}$ and $x_{i 0}^{T} \bar{M}_{i} x_{i 0}$.

This minimax linear quadratic technique minimizes the following performance cost over all permissible integral quadratic constraints (IQCs):

$$
J_{w c}(u) \triangleq \int_{0}^{\infty} \sum_{i=1}^{N}\left\|z_{i}(t)\right\|^{2} d t .
$$

In this paper we consider norm bounded constraints, as in (30), instead of the more general IQCs. This means that the designed controllers are suboptimal for norm bounded constraints. The control algorithm is to find the infimum of the following function over the set $\mathcal{T}$ :

$$
J(\tau, \theta)=\sum_{i=1}^{N} x_{i 0}^{T}\left[\bar{X}_{i}+\tau_{i} M_{i}+\theta_{i} \bar{M}_{i}\right] x_{i 0},
$$

where $\mathcal{T}=\left\{\left\{\tau_{i} \theta_{i}\right\} \in R^{2 N}, \tau_{i}>0, \theta_{i}>0\right\}, M_{i}>0$ and $\bar{M}_{i}>0$ are two sets of symmetric matrices, and matrices $\bar{X}_{i}$ and $\bar{Y}_{i}$ are the solutions to the following pair of coupled generalized algebraic Riccati equations and algebraic Riccati inequalities [28]:

$$
\begin{aligned}
& A_{i}^{T} \bar{X}_{i}+\bar{X}_{i} A_{i}+\bar{C}^{T}{ }_{i} \bar{C}_{i}-\bar{X}_{i}\left[B_{i} R_{i}^{-1} B_{i}^{T}-\bar{B}_{2_{i}} \bar{B}_{2_{i}}^{T}\right] \bar{X}_{i}=0 \\
& A_{i}^{T} \bar{Y}_{i}+\bar{Y}_{i} A_{i}+\bar{Y}_{i} \bar{B}_{2_{i}} \bar{B}_{2_{i}}^{T} \bar{Y}_{i}-\left[C_{y_{i}}^{T} W_{i}^{-1} C_{y_{i}}-\bar{C}_{i}^{T} \bar{C}_{i}\right]<0
\end{aligned}
$$

where $R_{i}=\bar{D}_{i}^{T} \bar{D}_{i}, W_{i}=\bar{D}_{y_{i}} \bar{D}_{y_{i}}^{T}, \bar{\theta}_{i}=\sum_{n=1, n \neq i}^{N} \theta_{n}$,

$$
\begin{gathered}
\bar{C}_{i}=\left[\begin{array}{c}
C_{i} \\
\left(\tau_{i}+\bar{\theta}_{i}\right)^{1 / 2} H_{i}
\end{array}\right], \quad \bar{D}_{i}=\left[\begin{array}{c}
D_{i} \\
\left(\tau_{i}+\bar{\theta}_{i}\right)^{1 / 2} G_{i}
\end{array}\right], \\
\bar{B}_{2_{i}}=\left[\begin{array}{ll}
\tau_{i}^{-1 / 2} E_{i} & \theta_{i}^{-1 / 2} L_{i}
\end{array}\right], \quad \bar{D}_{y_{i}}=\left[\begin{array}{ll}
\tau_{i}^{-1 / 2} D_{y_{i}} & 0
\end{array}\right] .
\end{gathered}
$$

The controller $u_{i}^{*}$ with the $\tau^{*}, \theta^{*}$ is given by [28]:

$$
\begin{aligned}
\dot{x}_{c_{i}}= & \left\{A_{i}-\left[B_{i} R^{-1} B_{i}^{T}-\bar{B}_{2_{i}} \bar{B}_{2_{i}}^{T}\right] \bar{X}_{i}\right\} x_{c_{i}} \\
& +\left[\bar{Y}_{i}-\bar{X}_{i}\right]^{-1} C_{y_{i}}^{T} W_{i}^{-1}\left[y_{i}-C_{y_{i}} x_{c_{i}}\right], \\
u_{i}^{*}= & -R_{i}^{-1} B_{i}^{T} \bar{X}_{i} x_{c_{i}} .
\end{aligned}
$$

The solutions are required to satisfy the following conditions: $\tau_{i}>0, \theta_{i}>0, \bar{X}_{i} \geq 0, \bar{Y}_{i} \geq 0$ and $\bar{Y}_{i}>\bar{X}_{i}$.

The controller $u^{*}$ guarantees the following minimax property

$$
J_{w c}\left(u^{*}\right) \leq J\left(\tau^{*}, \theta^{*}\right)=\inf _{\mathcal{T}} J(\tau, \theta)
$$

The solution of the optimization problem using the LMI technique is discussed in Section 10. 


\section{Control Design Algorithm}

The controller, in this section, is designed for severe faults so it can, in principle, also ensure stability against other disturbances. From fault simulations we estimated the operating region $\Omega$ formed by corner points

$\left[\bar{s}_{i}, \bar{E}_{d r_{i}}^{\prime}, \bar{E}_{q r_{i}}^{\prime}, \bar{\omega}_{m_{i}}, \bar{\omega}_{G_{i}}, \bar{\gamma}_{i}, \bar{v}_{d c_{i}}, \bar{v}_{t m_{i}}, \bar{v}_{s c_{i}}\right]^{T}$ and $\left[\underline{\mathrm{s}}_{i}, \underline{\mathrm{E}}_{d r_{i}}^{\prime}, \underline{\mathrm{E}}_{q r_{i}}^{\prime}, \underline{\omega}_{m_{i}}, \underline{\omega}_{G_{i}}, \underline{\gamma}_{i}, \underline{\mathrm{v}}_{d c_{i}}, \underline{\mathrm{v}}_{t m_{i}}, \underline{\mathrm{v}}_{s c_{i}}\right]^{T}$

centred at equilibrium point for severe faults with the values $\bar{s}_{i}-\underline{\mathrm{s}}_{i}=2 \times 0.225 \mathrm{pu}, \bar{E}_{d r_{i}}^{\prime}-\underline{\mathrm{E}}_{d r_{i}}^{\prime}=2 \times 0.242 \mathrm{pu}$, $\bar{E}_{q r_{i}}^{\prime}-\underline{\mathrm{E}}_{q r_{i}}^{\prime}=2 \times 0.225 \mathrm{pu}, \bar{\omega}_{m_{i}}-\underline{\omega}_{m_{i}}=2 \times 0.395 \mathrm{pu}, \bar{\omega}_{G_{i}}-\underline{\omega}_{G_{i}}=2 \times 0.337 \mathrm{pu}, \bar{\gamma}_{i}-\underline{\gamma}_{i}=2 \times 25^{\circ}, \bar{v}_{d c_{i}}-\underline{\mathrm{v}}_{d c_{i}}=$ $2 \times 0.334 \mathrm{pu}, \bar{v}_{t m_{i}}-\underline{\mathrm{v}}_{t m_{i}}=2 \times 0.235 \mathrm{pu}, \bar{v}_{s c_{i}}-\underline{\mathrm{v}}_{s c_{i}}=2 \times 0.248 \mathrm{pu}, \bar{m}_{i}-\underline{\mathrm{m}}_{i}=2 \times 0.328$ and $\bar{\alpha}_{i}-\underline{\alpha}_{i}=2 \times 28^{\circ}$, $i=1,2$. The design process is described in the following steps:

(i) From simulations, select coherent groups of generating units and represent them by equivalent models.

(ii) Perform modal analysis and determine the critical modes. Analyze the participation vectors for the critical modes and identify the states related to them.

(iii) From the simulations of the faulted system (undergoing a large perturbation during the LVRT transient), obtain the range in variations of all state variables and form a volume, $\Omega$, with corner points given by $\left(x_{f_{p}}-x_{0_{p}}\right)$ and $\left(x_{f_{p}}+x_{0_{p}}\right)$, $p=1, \ldots, 7$, where $2 x_{f_{p}}$ is the largest variation in the $p^{\text {th }}$ state variable about its equilibrium value, $x_{0_{p}}$.

(iv) Obtain $\Gamma_{i}^{*}=\max _{x_{i}^{* p} \in \Omega_{i}}\left\{\Gamma_{i}:\left\|\phi_{i}\right\|^{2}<1,\left\|\Xi_{i}\right\|^{2}<1\right\}$, as given in (28). The process to obtain $\Gamma_{i}^{*}$ involves obtaining the maximum value of $\tilde{\phi}_{i}, \tilde{\psi}_{i}$, and $\Xi_{i}$ over the entire region of interest and then using (27) to choose $\Gamma_{i}$ such that $\left\|\phi_{i}\right\|^{2}<1$ and $\left\|\Xi_{i}\right\|^{2}<1$.

(v) Check if there exists a feasible controller with $\Gamma_{i}=\Gamma_{i}^{*}$, i.e., scalars $\tau_{i}$ and $\theta_{i}$ exist such that there is a feasible solution to LMIs, as described in Section 10.

(vi) Compare the control region with the operating region required to provide the LVRT capability of wind generators.

(vii) If we obtain a feasible controller in the above step, increase the range of the operating region if step (vi) is not satisfied or, if we have arrived at the largest possible range then perform an optimal search over the scalar parameters $\tau_{i}$ and $\theta_{i}$, to get the infimum in (6). If there is no feasible solution with the chosen $\Gamma_{i}=\Gamma_{i}^{*}$, reduce the range and go to step (iv).

For the given system, we are able to obtain feasible controllers with values of $\Gamma_{1}=0.968$ and $\Gamma_{2}=0.976$. The controller is stabilising for all variation of states in the polytope region $\Omega$ formed by corner points $\left[\bar{s}_{i}, \bar{E}_{d r_{i}}^{\prime}, \bar{E}_{q r_{i}}^{\prime}, \bar{\omega}_{m_{i}}, \bar{\omega}_{G_{i}}, \bar{\gamma}_{i}, \bar{v}_{d c_{i}}, \bar{v}_{t m_{i}}, \bar{v}_{s c_{i}}\right]^{T}$ and $\left[\underline{\mathrm{s}}_{i}, \underline{\mathrm{E}}_{d r_{i}}^{\prime}, \underline{\mathrm{E}}_{q r_{i}}^{\prime}, \underline{\omega}_{m_{i}}, \underline{\omega}_{G_{i}}, \underline{\gamma}_{i}, \underline{\mathrm{v}}_{d c_{i}}, \underline{\mathrm{v}}_{t m_{i}}, \underline{\mathrm{v}}_{s c_{i}}\right]^{T}$ with the following values: $\bar{s}_{i}=s_{i 0}+0.243 \mathrm{pu}, \underline{\mathrm{s}}_{i}=s_{i 0}-0.243 \mathrm{pu}, \bar{E}_{d r_{i}}^{\prime}=E_{d r_{i 0}}^{\prime}+0.347 \mathrm{pu}, \bar{E}_{d r_{i}}^{\prime}=E_{d r_{i 0}}^{\prime}-0.347$ $\mathrm{pu}, \bar{E}_{q r_{i}}^{\prime}=E_{q r_{i 0}}^{\prime}+0.315 \mathrm{pu}, \underline{\mathrm{E}}_{q r_{i}}^{\prime}=E_{q r_{i 0}}^{\prime}-0.315 \mathrm{pu}, \bar{\omega}_{m_{i}}=\omega_{m_{i 0}}+0.428 \mathrm{pu}, \underline{\omega}_{m_{i}}=\omega_{m_{i 0}}-0.428 \mathrm{pu}, \bar{\omega}_{G_{i}}=$ $\omega_{G_{i 0}}+0.437 \mathrm{pu}, \underline{\omega}_{G_{i}}=\omega_{G_{i 0}}-0.437 \mathrm{pu}, \bar{\gamma}_{i}=\gamma_{i 0}+36^{\circ}, \bar{\gamma}_{i}=\gamma_{i 0}-36^{\circ}, \bar{v}_{d c_{i}}=v_{d c_{i 0}}+0.365 \mathrm{pu}, \underline{\mathrm{v}}_{d c_{i}}=v_{d c_{i 0}}-0.365 \mathrm{pu}$, $\bar{v}_{t m_{i}}=v_{t m_{i 0}}+0.269 \mathrm{pu}, \underline{\mathrm{v}}_{t m_{i}}=v_{t m_{i 0}}-0.269 \mathrm{pu}, \bar{v}_{s c_{i}}=v_{s c_{i 0}}+0.275 \mathrm{pu}, \bar{m}_{i}=m_{i 0}-0.467, \bar{\alpha}_{i}=\alpha_{i 0}+23^{\circ}$ and $\underline{\alpha}_{i}=\alpha_{i 0}-23^{\circ}, i=1,2$. This range of the variation of the state variables is larger than the range for several large disturbances as noted earlier in this subsection. The above bound for $\phi(\zeta)$ is obtained at a point interior to the region, i.e., $s_{i}^{*}=0.185 \mathrm{pu}, E_{d r_{i}}^{\prime *}=0.85 \mathrm{pu}, E_{q r_{i}}^{\prime *}=0.825 \mathrm{pu}, \omega_{m_{i}}^{*}=1.45 \mathrm{pu}, \omega_{G_{i}}^{*}=1.42 \mathrm{pu}, \gamma_{i}^{*}=25.5^{\circ}, v_{d c_{i}}^{*}=$ $0.86 \mathrm{pu}, v_{s c_{i}}^{*}=0.845 \mathrm{pu}, m_{i}^{*}=0.425 \mathrm{pu}$ and $\alpha_{i}^{*}=22.5^{\circ}, i=1,2$. Although the designed controller is not globally stabilising but we know that it is stabilising over a large operating region which covers most faulted system operation. From the two cross-sections from the polytope $\Omega$ shown in Figure 6(a), it can be seen that the region of controller operation is larger than the region of faulted system trajectories.

\section{Controller Performance Evaluation}

\section{A. Enhancement of voltage and transient stability margins}

The LVRT capability of a wind generator is expressed in this paper as voltage and transient stability margins. The voltage stability margin is defined as the difference between the operating voltage and the critical voltage. The transient stability margin is given as the difference between the speed after a specified fault duration and the critical speed (CS) of the generator. The critical speed is given by the intersection between the torque-speed curve for the specified system and the 
TABLE II

Performance Comparison: $(a)$ Proposed controller; And $(c)$ PI-Based STATCOM/ESS

\begin{tabular}{|c|c|c|c|c|c|c|}
\hline \multirow{2}{*}{ STATCOM/ESS } & \multicolumn{3}{|c|}{ (a) Proposed Controller } & \multicolumn{3}{c|}{ (c) PI Control } \\
\cline { 2 - 7 } & CS & CCT & Critical voltage & CS & CCT & Critical voltage \\
\hline 150 MVA/95 F & $1.35 \mathrm{pu}$ & $0.165 \mathrm{~s}$ & $0.605 \mathrm{pu}$ & $1.315 \mathrm{pu}$ & $0.140 \mathrm{~s}$ & $0.625 \mathrm{pu}$ \\
\hline
\end{tabular}

mechanical torque [30]. The critical voltage can be obtained from the P-V curves [31]. The stability analysis of a power system may consider the determination of its critical clearing time (CCT), for a given fault, in order to find the maximum value of the CCT for which the system is still stable. In this paper, the CCT is first estimated by using (44) and then exact value is determined from simulations in which it is obtained by increasing the fault time interval until the system loses its stability [36].

$$
t_{c}=\frac{1}{T_{m}} 2 H_{m}\left(s_{c}-s_{0}\right),
$$

where $t_{c}$ is the critical clearing time, $s_{c}$ the critical slip and $s_{0}$ the slip at equilibration point of a generator.

A simulation study is performed to emulate the system in Fig 2 with the purpose of evaluating the transient and voltage stability limits achievable with the proposed and PI-based STATCOM/ESS. The critical clearing time (CCT) and critical speed (CS), as shown in Table II, for a three-phase fault with 150 MVA STATCOMs and 95 F, 19 kJ supercapacitors are $0.165 \mathrm{~s}$ and $1.35 \mathrm{pu}$ with the designed controller, compared with $0.140 \mathrm{~s}$ and $1.315 \mathrm{pu}$ with a properly tuned PI controller [20]. In this case, the gain of the tuned (trial and error method) PI controller is obtained as $K_{P}=0.28$ and $K_{I}=$ 20.45. It can be concluded that an appropriate combination of active and reactive power control by STATCOM/ESS is an effective way of improving the stability and enhancing the fault ride-through capability of the relevant induction-generatorbased wind turbines.

In order to evaluate the performance of the designed controller, in the face of system nonlinearity and operating conditions, detailed simulations are performed for a symmetrical 3-phase fault at bus 11 which is subsequently cleared after $150 \mathrm{~ms}$. Figs. 4(a) and 4(b) show the speed response and terminal voltages, respectively, of the wind farm $W F_{1}$ with the conventional PI controller and the proposed STATCOM/ESS controller. During the fault, the wind generator accelerates, since it is no longer able to generate enough electromagnetic torque to balance the mechanical torque coming from the wind which is obviously unaffected by the grid fault. When the fault is cleared, the generator speed with the proposed control is about $1.15 \mathrm{pu}$ whereas that with the PI control is $1.6 \mathrm{pu}$. The reclosing time, speed and voltage using the PI controller is greater than the corresponding CCT, CS and critical voltage with the proposed controller. With the PI controller it can be seen that the terminal voltage cannot be restored and the induction generator continues to accelerate until the system loses stability.

\section{B. Comparisons with standard LVRT requirements}

Interconnection standards vary from country to country and among individual provinces or states, depending on local grid characteristics and utility specific requirements. In this research work the standard jointly recommend by the North American Electric Reliability Council (NAERC) and the American Wind Energy Association (AWEA) [34] is used. This standard demands that if the voltage remains at a level greater than $15 \%$ of the nominal voltage for a period that does not exceed 0.625 seconds, the plant must stay online. Ireland also follows a similar standard [35]. Although this standard is followed in this research work, the designed controller fulfils the some other grid codes as well. Fig. 5 shows the terminal voltage of the wind farm $W F_{2}$ with the the proposed STATCOM/ESS controller with zero voltage for the duration of $300 \mathrm{~ms}$ from which it is clear that the proposed control can meet the standard requirement of the LVRT capability. The reason of providing stability during the LVRT transient is clear from Figs. 6(a) and 6(b), which show that the control region provided by the designed controller is larger than the area required for the LVRT. Similar comparison holds true for other state variables. 


\section{Impact of adding supercapacitors}

To test the effects of adding supercapacitor, a simulation is performed with (i) STATCOM/ESS, and (ii) STATCOM only. A three phase fault is applied at middle of the line 16-17 at $1 \mathrm{~s}$ and the fault is cleared after $140 \mathrm{~ms}$ by opening the line 16-17. This line is again restored after $150 \mathrm{~ms}$. Figs. 7(a) and 7(b) show the voltage and real power output of $W F_{2}$ from which, it is clear that although the addition of supercapacitor does not produce significant difference in terminal voltage response, however, it damps the oscillation in output power quickly. The active power is controlled using energy storage type supercapacitor and this is effective to enhance the transient stability of the rest of the system.

\section{CONCLUSiOnS}

In this paper, a new robust decentralized STATCOM/ESS control has been proposed to enhance the LVRT capability of fixed-speed wind turbines. A systematic procedure to design the controller has been discussed. The designed controller guarantees stability if the system post-fault operating point is in the region for which the controller is designed. A tenmachine power system has been used to evaluate the performance of the designed controller. Simulation results show that despite the nonlinear interconnections between different types of generators and significant operating condition variations

following fault, the proposed controller can greatly enhance the transient and voltage stability as well as LVRT capability of wind turbines. The future perspective of this work is to design reduced order controllers for distributed systems.

\section{REFERENCES}

[1] Leon, J. A. D. D. and Taylor, C. W.: 'Understanding and solving short term voltage instability'. Proc. IEEE Power Eng. Society Summer Meeting, Chicago, Illinois, July 2002, pp. 745-752

[2] De Alegra, I. M., Andreu, J., Martin, J. L., Ibañez, P., Villate, J. L., and Camblong, H.: 'Connection requirements for wind farms: A survey on technical requirements and regulation'. Renewable and Sustainable Energy Reviews, 2007, 11, (8), pp. 1858-1872

[3] Suul, J. A., Molinas, M., and Undeland, T.: 'STATCOM-based indirect torque control of induction machines during voltage recovery after grid faults,' IEEE Trans. on Power Electronics, 2010, 25, (5), pp. 1240-1250

[4] El-Moursi, M. S., Bak-Jensen, B., and Abdel-Rahman, M. H.: 'Novel STATCOM controller for mitigating SSR and damping power system oscillations in a series compensated wind park'. IEEE Trans. on Power Elec., 2010, 25, (2), pp. 429-441

[5] Rahimi, M., and Parniani, M.: 'Efficient control scheme of wind turbines with doubly fed induction generators for low-voltage ride-through capability enhancement'. IET Renewable Power Generation, 2010, 4, (3), pp. 242-252

[6] Singh, B., and Kasal, G. K.: 'Voltage and frequency controller for a three-phase four-wire autonomous wind energy conversion system'. IEEE Trans. on Energy Conversion, 2008, 23, (2), pp. 509-518

[7] Kamwa, I., Grondin, R., and Hebert, Y.: 'Wide-area measurement based stabilizing control of large power systems-a decentralized/hierarchical approach'. IEEE Trans. on Power Systems, 2001, 16, (1), pp. 136-153

[8] Hossain, M. J., Pota, H. R., and Kumble, C.: 'Decentralized robust static synchronous compensator control for wind farms to augment dynamic transfer capability'. Journal of Renewable and Sustainable Energy, 2010, 2, (2), pp. 022 701(1)-022 701(20)

[9] Siljak, D. D., Zecevic, A. I., and Neskovic, G.: 'Robust decentralized exciter control with linear feedback'. IEEE Trans. on Power Systems, 2004, 19, (2), pp. 1096-1103

[10] Guo, Y., Hill, D. J., and Wang, Y.: 'Nonlinear decentralized control of large-scale power systems'. Automatica, 2000, 36, (9), pp. $1275-1289$

[11] Siljak, D. D., Stipanovic, D. M., and Zecevic, A. I.: 'Robust decentralized turbine/governor control using linear matrix inequalities'. IEEE Trans. on Power Systems, 2002, 17, (3), pp. 715-722

[12] Siljak, D. D., and Zecevic, A. I., 'Control of large-scale systems: Beyond decentralized feedback'. Annual Reviews in Control, 2005, 29, (2), pp. 169-179

[13] Hossain, M. J., Pota, H. R., Ugrinovskii, V., and Ramos, R. A.: 'Simultaneous STATCOM and pitch angle control for improved LVRT capability of fixed-speed wind turbines'. IEEE Trans. on Sustainable Energy, in press, 2010, 1, (3)

[14] Guo, Y., Hill, D. J., and Wang, Y.: 'Global transient stability and voltage regulation for power systems'. IEEE Trans. on Power Systems, 2001, 16, (4), pp. 678-688

[15] Hossain, M. J., Pota, H. R., Ugrinovskii, V., and Ramos, R. A.: 'Excitation control for large disturbances in power systems with dynamic loads'. Proc. IEEE Power and Energy Society General Meeting, Calgary, Canada, July 2009, pp. 1-8 
[16] Hossain, M. J., Pota, H. R., and Ugrinovskii, V.: 'Short and long-term dynamic voltage instability'. Proc. 17th IFAC World Congress, Seoul, Korea, July 2008, pp. 9392-9397

[17] Ackermann, T.: Wind Power in Power Systems (England: John Wiley and Sons, Ltd, 2005)

[18] Abdin, E. S., and Xu, W.: 'Control design and dynamic performance analysis of a wind turbine-induction generator unit'. IEEE Trans. on Energy Conversion, 2000, 15, (1), pp. 91-96

[19] Nandigam, K., and Chowdhury, B. H.: 'Power flow and stability models for induction generators used in wind turbines'. Proc. IEEE Power Eng. Society General Meeting, June 2004, pp. 2012-2016

[20] Srithorn, P., Sumner, M., Yao, L., and Parashar, R.: 'A STATCOM with supercapacitors for enhanced power system stability'. Proc. 4th IET Conference on Power Electronics, Machines and Drives, London, April 2008, pp. 96-100

[21] I. A. Hiskens. Power system test cases. [Online]. Available: http://psdyn.ece.wisc.edu/IEEE_benchmarks/. , accessed 1999

[22] Fernandez, L., Garcia, C., Saenz, J., and Jurado, F.: 'Equivalent models of wind farms by using aggregated wind turbines and equivalent winds'. Energy Conversion and Management, 2009, 50, (3), pp. 691-704

[23] Germond, A. J.and Podmore, R.: 'Dynamic aggregation of generating unit models'. IEEE Trans. on Power Appa. and Syst., 1978, PAS-97, (4), pp. 1060-1069

[24] Pal, B. C., Coonick, A. H., and Macdonald, D. C., 'Robust damping controller design in power systems with superconducting magnetic energy storage devices'. IEEE Trans. on Power Systems, 2000, 15, (1), pp. 320-325

[25] Werner, H., Korba, P., and Yang, T. C.: 'Robust tuning of power system stabilizers using LMI-techniques' IEEE Trans. on Control Systems Technology, 2003, 11, (2), pp. 147-152

[26] Khalil, H. K.: Nonlinear Systems (Macmillan, New York: Prentice-Hall, 1992)

[27] Petersen, I. R., Ugrinovskii, V. A., and Savkin, A. V.: Robust Control Design Using $H_{\infty}$ Methods (London: Springer, 2000)

[28] Li, L., Ugrinovskii, V. A., and Orsi, R.: 'Decentralized robust control of uncertain markov jump parameter systems via output feedback'. Automatica, 2007, 43, (11), pp. 1932-1944

[29] Li, L., and Petersen, I. R.: 'A rank constrained LMI algorithm for the robust $H_{\infty}$ control of an uncertain system via a stable output feedback controller'. Proc. 46th IEEE Conf. on Decision and Control, New Orleans, Louisiana, USA, December 2007, pp. 5423-5428

[30] Akhmatov, V., Knudsen, H., Bruntt, M., Nielsen, A., Pedersen, J. K., and Poulsen, N. K.: 'A dynamic stability limit of grid-connected induction generator'. Proc. Int. Conf. on Power and Energy Systems, September 2000, pp. 235-244

[31] Cutsem, T. V.and Vournas, C. D.: Voltage Stability of Electric Power System (Norwell, MA: Knower Academic, 1998)

[32] Bary, D.: 'Increasing renewable accessibility in Ireland'. Proc. 9th World Energy Congr., September 2004, pp. 1-10

[33] Li, L., and Ugrinovskii, V. A.: 'On necessary and sufficient conditions for $H_{\infty}$ output feedback control of markov jump linear systems'. IEEE Trans. on Automatic Control, 2007, 52, (7), pp. 1287-1292

[34] Interconnection for Wind Energy. FERC Stats. \& Regs. 31,186 (2005), Order No. 661, 70 Fed. Reg. 34993

[35] Wu, Q., Xu, Z. and Ostergaard, J.: 'Grid Integration Issues for Large Scale Wind Power Plants (WPPs)'. IEEE Power and Energy Society General Meeting, 25-29 July 2010, Minneapolis, Minnesota, USA, pp. 1-7.

[36] Hemeida, A. M.: 'Improvement of Voltage stability and Critical Clearing Time for Multi-machine Power Systems Using Static VAR Compensator'. ICGST-ACSE, December 2009, 9, (2), pp. 41-47.

\section{APPENDIX}

The suboptimal control design used in this paper involves solving the optimization problem given on the right-hand side of (43). Generally, it is difficult to provide a systematic way to perform such optimization. In this paper, the idea is to replace the problem $\inf _{\tau} J(\tau, \Theta)$ with an equivalent optimization problem involving rank constrained linear matrix inequalities (LMIs) [33]. From (39), we get

$$
A_{i}^{T} \bar{X}_{i}+\bar{X}_{i} A_{i}+\bar{C}^{T}{ }_{i} \bar{C}_{i}-\bar{X}_{i}\left[B_{i} R_{i}^{-1} B_{i}^{T}-\bar{B}_{2_{i}} \bar{B}_{2_{i}}^{T}\right] \bar{X}_{i}<0,
$$

by multiplying the left and right sides of (45) with $\tilde{X}_{i}=\bar{X}_{i}^{-1}$, we get

$$
\tilde{X}_{i} A_{i}^{T}+A_{i} \tilde{X}_{i}+\tilde{X}_{i} \bar{C}^{T}{ }_{i} \bar{C}_{i} \tilde{X}_{i}-\left[B_{i} R_{i}^{-1} B_{i}^{T}-\bar{B}_{2_{i}} \bar{B}_{2_{i}}^{T}\right]<0 .
$$

Introducing matrices $F_{i}$ of appropriate dimensions, without changing the feasibility of (46), we add a quadratic term of $F_{i}$ to the left side of (46) as follows, 


$$
\tilde{X}_{i} A_{i}^{T}+A_{i} \tilde{X}_{i}+\tilde{X}_{i} \bar{C}^{T}{ }_{i} \bar{C}_{i} \tilde{X}_{i}-\left[B_{i} R_{i}^{-1} B_{i}^{T}-\bar{B}_{2_{i}} \bar{B}_{2_{i}}^{T}\right]+\left[F_{i}^{T}+B_{i} R^{-1}\right] R_{i}\left[F_{i}^{T}+B_{i} R_{i}^{-1}\right]^{T}<0,
$$

which is equivalent to

$$
\tilde{X}_{i} A_{i}^{T}+A_{i} \tilde{X}_{i}+\tilde{X}_{i} \bar{C}^{T}{ }_{i} \bar{C}_{i} \tilde{X}_{i}+\bar{B}_{2_{i}} \bar{B}_{2_{i}}^{T}+F_{i}^{T} R_{i} F_{i}+B_{i} F_{i}+F_{i}^{T} B_{i}^{T}<0 .
$$

Using (40), the terms of (48) can be represented as follows

$$
\begin{aligned}
\bar{B}_{2_{i}} \bar{B}_{2_{i}}^{T} & =\tau_{i}^{-1} E_{i} E_{i}^{T}+\Theta_{i}^{-1} L_{i} L_{i}^{T}, \\
\tilde{X}_{i} \bar{C}^{T}{ }_{i} \bar{C}_{i} \tilde{X}_{i} & =\tilde{X}_{i}\left[C_{i}^{T} C_{i}+\left(\tau_{i}+\bar{\Theta}_{i}\right) H_{i}^{T} H_{i}\right] \tilde{X}_{i}, \\
F_{i}^{T} R_{i} F_{i} & =F_{i}^{T}\left[D_{i}^{T} D_{i}+\left(\tau_{i}+\bar{\Theta}_{i}\right) G_{i}^{T} G_{i}\right] F_{i} .
\end{aligned}
$$

Let $\tilde{\tau}_{i}=\tau_{i}^{-1}, \tilde{\Theta}_{i}=\Theta_{i}^{-1}$. By combining (48), (49) and applying the Schur complement, we obtain the following LMIs with variables $\tilde{X}_{i}, F_{i}, \tilde{\Theta}_{i}, \tilde{\tau}_{i}$ :

$$
\left[\begin{array}{cccc}
Z_{i} & \tilde{X}_{i} C_{i}^{T} & F_{i}^{T} D_{i}^{T} & \alpha_{i} \\
\star & -I & 0 & 0 \\
\star & \star & -I & 0 \\
\star & \star & \star & -\Theta_{i}
\end{array}\right]<0
$$

where

$$
\begin{aligned}
Z_{i} & =\tilde{X}_{i} A_{i}^{T}+A_{i} \tilde{X}_{i}+\tilde{\tau}_{i} E_{i} E_{i}^{T}+\tilde{\Theta}_{i} L_{i} L_{i}^{T}+B_{i} F_{i}+F_{i}^{T} B_{i}^{T} \\
\alpha_{i} & =\left[F_{i}^{T} G_{i}^{T}+\tilde{X}_{i} H_{i}^{T}, \ldots, F_{i}^{T} G_{i}^{T}+\tilde{X}_{i} H_{i}^{T}\right] \quad \text { (N entries) } \\
\Theta_{i} & =\operatorname{diag}\left[\tilde{\tau}_{i} I, \tilde{\Theta}_{1} I, \ldots, \tilde{\Theta}_{i-1} I, \tilde{\Theta}_{i+1} I, \tilde{\Theta}_{N} I\right] .
\end{aligned}
$$

Similarly, by substituting (40), into (38) and applying the Schur complement, we obtain the LMIs with variables $\bar{Y}_{i}, F_{i}, \Theta_{i}, \tau_{i}$ :

$$
\left[\begin{array}{ccc}
\beta_{i} & \bar{Y}_{i} E_{i} & \bar{Y}_{i} L_{i} \\
\star & -\tau_{i} I & 0 \\
\star & \star & -\Theta_{i} I
\end{array}\right]<0,
$$

where

$$
\beta_{i}=A_{i}^{T} \bar{Y}_{i}+\bar{Y}_{i} A_{i}-\tau_{i} C_{y i}^{T}\left[D_{y i} D_{y i}^{T}\right]^{-1} C_{y i}+C_{i}^{T} C_{i}+\left(\tau_{i}+\bar{\Theta}_{i}\right) H_{i}^{T} H_{i}
$$

The coupling condition $\bar{Y}_{i}>\bar{X}_{i}>0$ is equivalent to

$$
\left[\begin{array}{cc}
\tilde{X}_{i} & I \\
I & \bar{Y}_{i}
\end{array}\right]>0 .
$$

Now consider the performance upper bound on the right hand side of (43). Note that minimizing $J(\tau, \Theta)$ is equivalent to minimizing $\left(\lambda_{1}+\lambda_{2}+\ldots+\lambda_{n}\right)$ subject to

$$
\lambda_{i}>x_{i 0}^{T}\left[\bar{X}_{i}+\tau_{i} M_{i}+\Theta_{i} \bar{M}_{i}\right] x_{i 0} .
$$


Using the Schur complement again, (54) is equivalent to the following LMIs:

$$
\left[\begin{array}{cccc}
\lambda_{i} & \Pi & x_{i 0}^{T} M_{i}^{1 / 2} & x_{i 0}^{T} \tilde{M}_{i}^{1 / 2} \\
\star & \tilde{X}_{i} & 0 & 0 \\
\star & \star & \tilde{\tau}_{i} I & 0 \\
\star & \star & \star & \tilde{\Theta}_{i} I
\end{array}\right]<0,
$$

here $\Pi=\left[\pi_{1}^{1 / 2} x_{i 0}^{T}, \ldots, \pi_{k}^{1 / 2} x_{i 0}^{T}\right]$. Also the conditions $\tilde{\tau}_{i}>0, \tau_{i}>0, \tilde{\tau}_{i} \tau_{i}=1, \tilde{\Theta}_{i}>0, \Theta_{i}>0, \tilde{\Theta}_{i} \Theta_{i}=1$ are equivalent to the rank constrained LMIs

$$
\begin{gathered}
{\left[\begin{array}{cc}
\tilde{\tau}_{i} & I \\
I & \tau_{i}
\end{array}\right] \geq 0, \quad \operatorname{rank}\left[\begin{array}{cc}
\tilde{\tau}_{i} & I \\
I & \tau_{i}
\end{array}\right] \leq 1,} \\
{\left[\begin{array}{cc}
\tilde{\Theta}_{i} & I \\
I & \Theta_{i}
\end{array}\right] \geq 0, \quad \operatorname{rank}\left[\begin{array}{cc}
\tilde{\Theta}_{i} & I \\
I & \Theta_{i}
\end{array}\right] \leq 1 .}
\end{gathered}
$$

We now consider the following linear cost optimization problem in the variables $\lambda_{i}, \tilde{X}_{i}, \bar{Y}_{i}, F_{i}, \tilde{\Theta}_{i}, \tilde{\tau}_{i}$ and $\tau_{i}, \Theta_{i}:[33]$

$$
J_{L M I}^{*} \triangleq \inf \left(\lambda_{1}+\ldots+\lambda_{n}\right)
$$

subject to (50), (52), (53), (55), (56) and (57).

\section{LIST OF FIGURES}

1 STATCOM/ESS control strategy. . . . . . . . . . . . . . . . . . 17

210 machine 39 bus study system. . . . . . . . . . . . . . . . . . . . 17

3 Block diagram of the uncertain system. . . . . . . . . . . . . . . . . . 17

4 Speed and terminal voltage for three-phase fault at bus 11 (Solid line designed and dash line PI-based STATCOM/ESS $) \ldots \ldots \ldots \ldots \ldots \ldots \ldots \ldots \ldots$

5 Terminal voltage with zero-voltage for $300 \mathrm{~ms} \ldots \ldots \ldots$

6 Operating and control region (Solid line control region and dashed line operating region during LVRT transient) . . . . . . . . . . . . . . . . . . . . . . 18

7 Voltage and real power output for a three-phase fault on line 16-17. (Solid line designed STATCOM/ESS controller and dash line STATCOM without ESS controller). . . . . . . . . . . . 19 


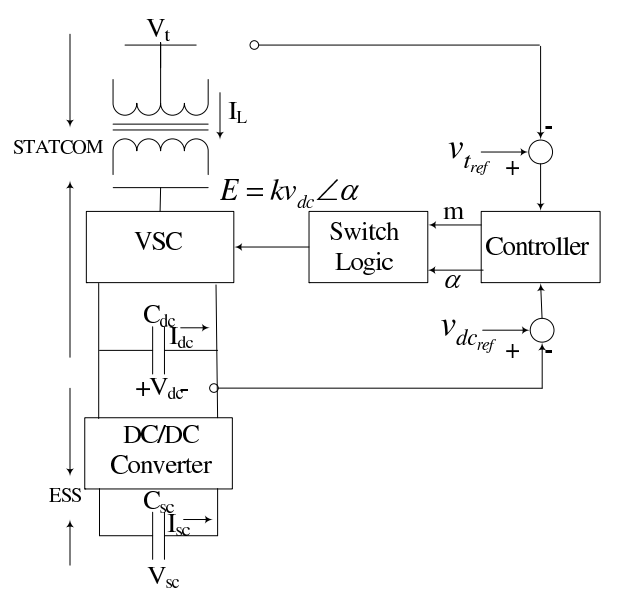

Fig. 1. STATCOM/ESS control strategy.

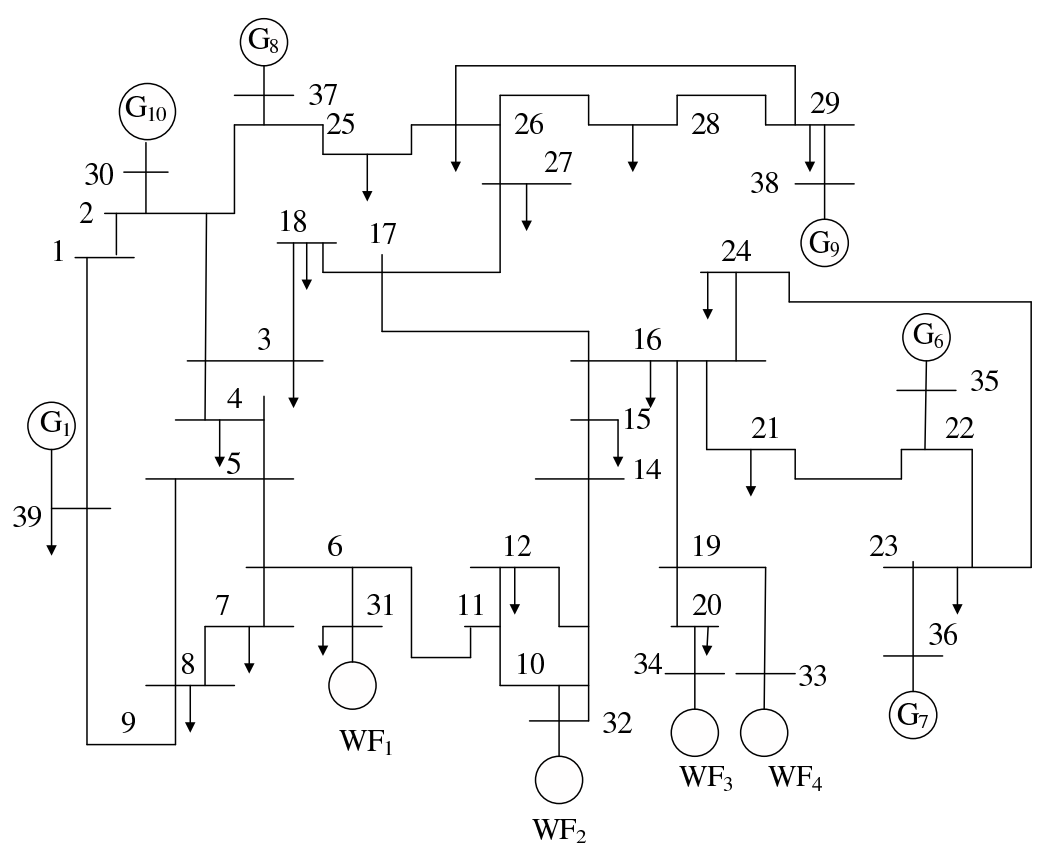

Fig. 2. 10 machine 39 bus study system.

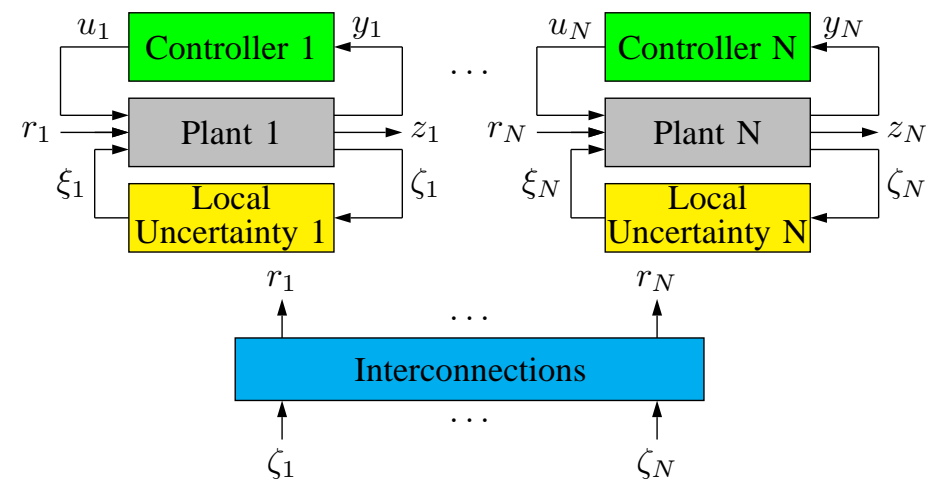

Fig. 3. Block diagram of the uncertain system. 


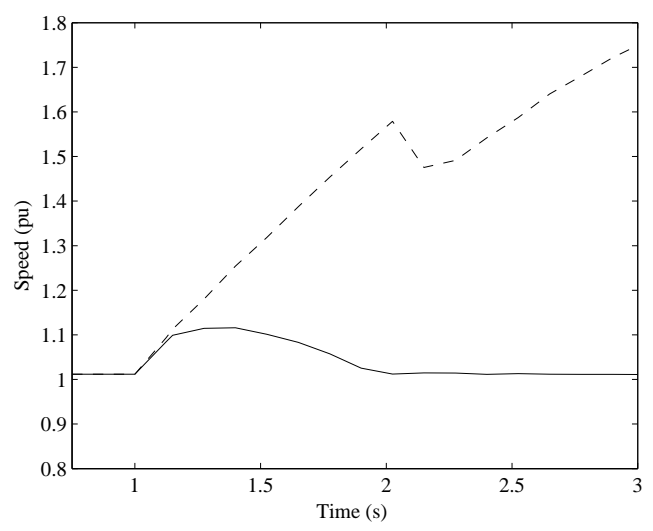

(a) Speed response

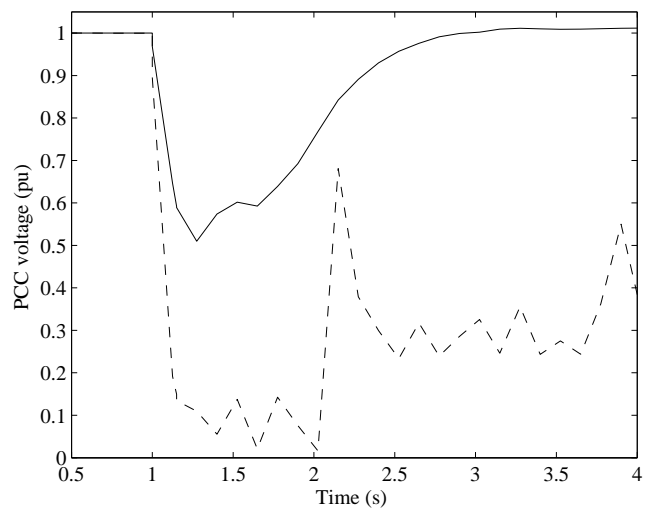

(b) Terminal voltage

Fig. 4. Speed and terminal voltage for three-phase fault at bus 11 (Solid line designed and dash line PI-based STATCOM/ESS )

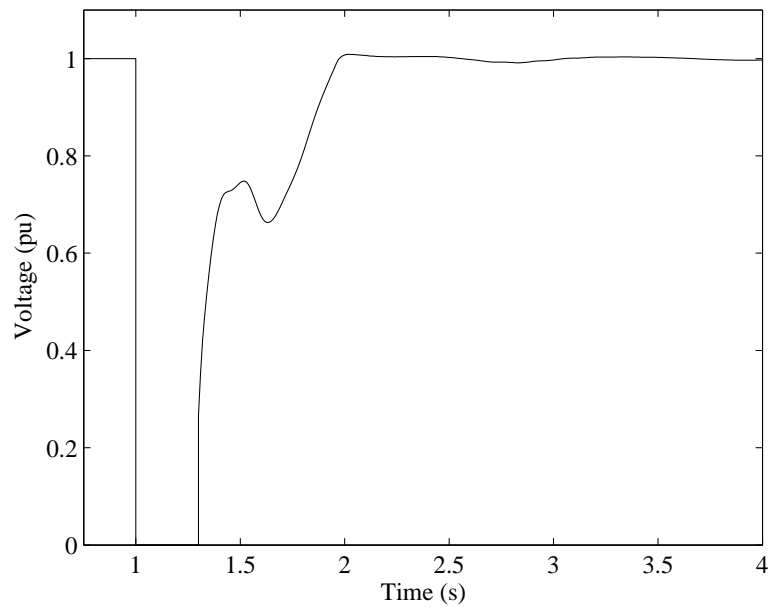

Fig. 5. Terminal voltage with zero-voltage for $300 \mathrm{~ms}$

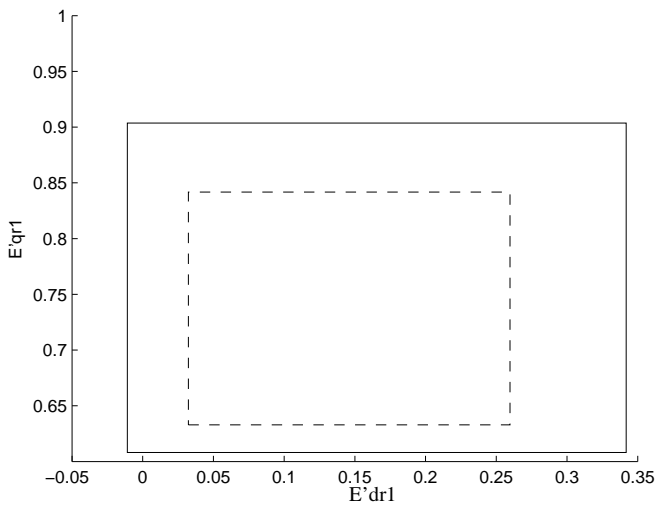

(a) D-axis \& q-axis transient emf polytope section

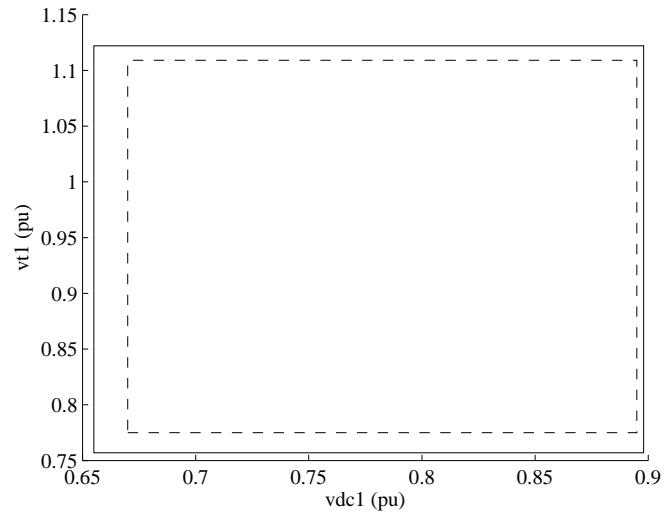

(b) Capacitor voltage \& terminal voltage polytope section

Fig. 6. Operating and control region (Solid line control region and dashed line operating region during LVRT transient) 


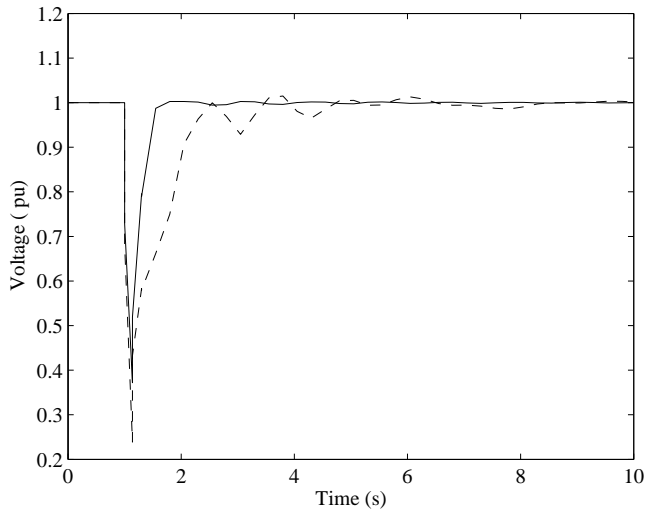

(a) Voltage response

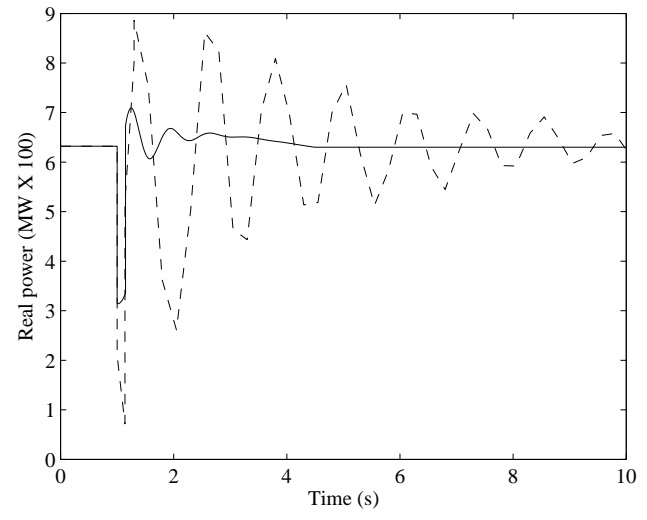

(b) Real power output

Fig. 7. Voltage and real power output for a three-phase fault on line 16-17. (Solid line designed STATCOM/ESS controller and dash line STATCOM without ESS controller). 